Research Article

\title{
Prescription auditing and drug utilization pattern in a tertiary care teaching hospital of western UP
}

\author{
Afroz Abidi*, Surabhi Gupta, Saurabh Kansal, Ramgopal
}

Department of Pharmacology, Subharti Medical College, Meerut-250005, U.P., India

Received: 12 October 2012 Accepted: 23 October 2012

\section{*Correspondence to:}

Dr. Afroz Abidi,

Email: afrozabidi@gmail.com

\begin{abstract}
Background: In India, a proper reporting of medication errors in the hospital is not available. Drugs worth crores of rupee are consumed every year but a substantial part of these drugs are irrationally prescribed. In order to promote rational drug usage standard policies on use of drugs must be set, and this can be done only after the current prescription practices have been audited. The prescriptions were analyzed based on the objectives of the study in order to promote rational use of drugs in a population.

Methods: The study was carried out prospectively over a period of two months and 15 days in general medicine OPD of our tertiary care hospital. A specially designed performa was used with pre-inserted carbons.

Results: Two hundred and thirty seven prescriptions were analyzed. Total no. of drugs in 237 prescriptions were 1001. Therefore average number of drugs/prescription is 4.22 . Drugs were prescribed by generic names in $3.79 \%$ of cases, drugs on EDL are only $53.25 \%$ and fixed dose combinations are $26.87 \%$ of total drugs. Dosage forms used were mostly oral $-93.51 \%$. Injectables were only $6.19 \%$ and topical forms were least $0.299 \%$. Doctors profile indicates that maximum number i.e. $93.67 \%$ were general practitioners. Basic information of patient was written in $72.57 \%$ prescriptions. Complete diagnoses were written in $70.04 \%$ prescriptions. Only $88.61 \%$ prescriptions were legible and only $76.79 \%$ prescriptions were complete in terms of dose, route, strength, frequency and dosage forms. Disease pattern seen was variable. Diseases of respiratory system were maximum $44.72 \%$ followed by infectious and parasitic diseases - $16.03 \%$ and diseases of digestive system $13.92 \%$. The most common drug groups prescribed were NSAIDs \pm serratiopeptidases, antibiotics, antihistaminics, multivitamins, minerals, enzymes and expectorants \& bronchodilators. The incidence of polypharmacy was also common with maximum number of drugs which were prescribed per prescription were four in $39.24 \%$ of prescriptions. The prescriptions also had other minor anomalies.

Conclusions: This study showed that there is scope for improvement in prescribing patterns in areas of writing generic names of drugs, essential drugs, writing legible and complete prescriptions. Polypharmacy was also evident from our study. Establishment and implementation of appropriate clinical guidelines, use of essential medicines list, public education about medicines and regular update to the clinicians will help in implementing the principles of rational pharmacotherapeutics.
\end{abstract}

Keywords: Prescription auditing, Drug utilization pattern, Rational pharmacotherapy

\section{INTRODUCTION}

Prescription auditing is a type of vigilance activity, which is beneficial in clinical practice in terms of reducing the burden of disease because of medication errors.
Rational use of drugs is multifaceted. Its medical, social and economic aspects are well reflected in the WHO definition: "Rational use of drugs requires that patients receive medications appropriate to their clinical needs, in doses that meet their own individual requirements for an 
adequate period of time, at the lowest cost to them and their community".

Irrational prescribing is a global problem. The rationality of prescribing pattern is of utmost importance because bad prescribing habits including misuse, overuse and underuse of medicines can lead to unsafe treatment, exacerbation of the disease, health hazards, economic burden on the patients and wastage of resources. Examples of irrational use of medicines include: polypharmacy, inadequate dosage, and use of antimicrobials even for non-bacterial infections, excessive use of injections when oral forms are available and inappropriate, self-medication and non-compliance to dosing regimes. ${ }^{1}$

Prescription errors are very common because doctors are humans and not machine. There are numerous ways to get rid of these medication errors like establishment of committees to coordinate policies on drug usage, appropriate implementation and enforced regulation of clinical guidelines, development and use of national essential medicines list, public education about medicines and avoidance of financial incentives from drug companies. Medical education in clinical pharmacology should include the principles of rational pharmacotherapeutics in the form of problem based learnings and interactive sessions. Another important method to ensure rational prescribing among doctors is prescription auditing which gives them an accurate feedback on their prescribing patterns. It can be done either prospectively or retrospectively. These methods should be implemented in all the hospitals in India to ensure rational prescriptions.

The specialist departments in teaching hospitals should define prescribing policies for clinical prescriptions, teaching and examinations based on its formulary.

In India there are numerous drug companies with thousands of products in their basket which leads to a stiff competition among themselves. These pharmaceutical companies encourage doctors to prescribe branded medicines in exchange for sponsorships, incentives and gifts. Therefore as clinical pharmacologist we should teach our students against the influences they are likely to encounter in future in their professional life, such as drug promotions by the pharmaceutical companies and peer pressure.

The World Health Organization (WHO) has formulated a set of "core prescribing indicators" for improvement in rational drug use in outpatient practice. It includes the prescribing indicators, the patient care indicators and the facility indicators. ${ }^{2}$ Based on these indicators, studies have been carried out all over the world and even in India. $^{3-8}$

The prescription audit studies have been conducted in different settings like OPD or IPD's in hospitals, in hospital pharmacies, in medical stores and by private medical practitioners attached to hospitals with the aim of improving the standards of medical care. Since no such study was carried out in our outpatient set up therefore we aimed to measure these indicators in our setting to obtain data for promoting rational drug use. Such studies on drug utilization are necessary to obtain baseline data on drug use and create a database for comparison with future studies. Hence the present study was carried out with the objectives of:

a) Obtaining information on demographic characteristics of the patients and doctors profile in our area.

b) Information on diagnosis pattern and disease pattern.

c) Collect information on number of drugs prescribed, their prescribing patterns and calculate the mean number of drugs per prescription.

d) Calculate the percentage of drugs prescribed from the Essential drug list.

e) Percentage of fixed dose combinations (FDCs) prescribed, the percentage of drugs prescribed by generic name and the number of antibiotics prescribed.

f) Calculate the percentage of prescription with complete diagnosis, legibility with signature of doctor present on the prescriptions.

g) Analyze the prescriptions for basic information of patient like, name, age sex and address of the patient and completeness of prescriptions in terms of dose, strength, route, frequency, duration and dosage forms of prescribed drugs.

\section{METHODS}

The study was carried out prospectively over a period of two months and 15 days in general medicine OPD of our tertiary care teaching hospital. A specially designed performa was used with pre-inserted carbons which were quite similar to the OPD cards. Before the start of the study all the doctors were explained the objectives of the study and method of using the specially designed performas. The doctors retained the carbon copy of all the prescriptions which were collected from time to time.

These prescriptions were analyzed based on the objectives of the study. The age and sex of patients and doctors profile were recorded. The clinical diagnosis, number of drugs prescribed, number of drugs prescribed from the Essential drug list, number of fixed dose combinations (FDCs), number of drugs prescribed by generic name and the number of antibiotics prescribed were analyzed.

The prescriptions were also analyzed for their legibility, presence of doctor's signature on the prescriptions, basic 
information of patients and completeness of prescriptions in terms of dose, strength, route, frequency and duration and dosage forms of prescribed drugs.

\section{RESULTS}

Two hundred and fifty prescriptions were collected in this period but only 237 were fit to be analyzed. Total number of drugs prescribed in 237 prescriptions orders were 1001. Therefore average number of drugs/prescription is 4.22 .
The demographic profiles of the patients were found to be: Age distribution of children ( $\leq 14$ years) constituted $15.18 \%$, adolescents (15-19 years) were $7.59 \%$, adults (20-60 years) formed $65.82 \%$ and $>60$ age group formed $5.90 \%$. Age was not written in $5.48 \%$ of the prescriptions. The proportion of males was higher at $60.33 \%$ as compared to females who were only $34.59 \%$. Sex was not written in $5.06 \%$ cases (Table 1 ).

Table 1: Demographic profile of patients.

\begin{tabular}{|c|c|c|}
\hline & Age Distribution & Number $(\boldsymbol{\%})$ \\
\hline 1. & Children $(\leq 14$ years $)$ & $36(15.18 \%)$ \\
\hline 2. & Adolescents $(15-19$ years $)$ & $18(7.59 \%)$ \\
\hline 3. & Adults $(20-60$ years $)$ & $156(65.82 \%)$ \\
\hline 4. & Above 60 years & $14(5.90 \%)$ \\
\hline & Sex Distribution & Number $(\%)$ \\
\hline 1. & Males & $143(60.33 \%)$ \\
\hline 2. & Females & $82(34.59 \%)$ \\
\hline
\end{tabular}

Table 2: Prescription profiles.

\begin{tabular}{|c|c|c|}
\hline & Parameters & Number of prescriptions (\%) \\
\hline 1. & Drugs were prescribed by generic names & $9(3.79 \%)$ \\
\hline 2. & Fixed dose combinations used & $97(40.92 \%)$ \\
\hline 3. & More than 1 antibiotic prescribed in & $11(4.64 \%)$ \\
\hline 4. & Follow up advice was written in & $54(22.78 \%)$ \\
\hline 5. & Referral & $5(2.11 \%)$ \\
\hline 6. & Doctors Profile & \\
\hline a) & General practitioners (MBBS, MD) & $222(93.67 \%)$ \\
\hline b) & Specialist doctors & $4(1.68 \%)$ \\
\hline c) & Interns and junior residents & $11(4.64 \%)$ \\
\hline 7. & Duration of treatment & \\
\hline a) & Single dose & $3(1.26 \%)$ \\
\hline b) & 1-2 days & $17(7.17 \%)$ \\
\hline c) & 3-5 days & $89(37.55 \%)$ \\
\hline d) & 6-7 days & $62(26.16 \%)$ \\
\hline e) & 8-10 days & $31(13.08 \%)$ \\
\hline f) & $>10$ days & $20(8.43 \%)$ \\
\hline 8. & $\begin{array}{l}\text { Basic information of patient written (Name, Age, } \\
\text { sex, Address) }\end{array}$ & $172(72.57 \%)$ \\
\hline 9. & Complete diagnosis written & $166(70.04 \%)$ \\
\hline 10. & Legibility & $210(88.61 \%)$ \\
\hline 11. & $\begin{array}{l}\text { Complete prescription in terms of dose, route, } \\
\text { strength, frequency and dosage forms }\end{array}$ & $182(76.79 \%)$ \\
\hline
\end{tabular}


Table 3: Drug profiles.

\begin{tabular}{|c|c|c|}
\hline & Parameters & Number of drugs (\%) \\
\hline 1. & Drugs on EDL & $533(53.25 \%)$ \\
\hline 2. & Fixed dose combinations used & $269(26.87 \%)$ \\
\hline 3. & Dosage forms & \\
\hline & Oral & $936(93.51 \%)$ \\
\hline & Injectables & $62(6.19 \%)$ \\
\hline & Topical & $3(0.299 \%)$ \\
\hline
\end{tabular}

Table 4: Disease pattern \& Diagnosis pattern.

\begin{tabular}{|c|c|c|}
\hline & Disease pattern & Number of prescriptions (\%) \\
\hline 1. & Diseases of respiratory system & $106(44.72 \%)$ \\
\hline 2. & Infectious and parasitic diseases & $38(16.03 \%)$ \\
\hline 3. & Diseases of digestive system (GIT) & $33(13.92 \%)$ \\
\hline 4. & Diseases of musculoskeletal system & $18(7.59 \%)$ \\
\hline 5. & Diseases of central nervous system & $10(4.22 \%)$ \\
\hline 6. & Diseases of cardiovascular system & $8(3.37 \%)$ \\
\hline 7. & Diseases of skin and subcutaneous tissues & $6(2.53 \%)$ \\
\hline 8. & Trauma cases & $5(2.11 \%)$ \\
\hline 9. & Others & $13(5.48 \%)$ \\
\hline & Diagnosis pattern & Number of prescriptions $(\boldsymbol{\%})$ \\
\hline 1. & 1 diagnosis & $203(85.65 \%)$ \\
\hline 2. & 2 diagnosis & $2(10.12 \%)$ \\
\hline 3. & 3 diagnosis & $2(0.84 \%)$ \\
\hline
\end{tabular}

Drugs were prescribed by generic names only in $3.79 \%$ of cases. Fixed dose combinations were used in $40.92 \%$ cases. More than one antibiotic was prescribed in $4.64 \%$ cases. Doctors profile indicates that maximum number i.e. $93.67 \%$ were general practitioners. Only $1.68 \%$ were specialist doctors and rest $4.64 \%$ were interns and junior residents. Follow up advice was written only in $22.78 \%$ prescriptions and referrals in $2.11 \%$ prescriptions. The duration of treatment seen was: Single dose was prescribed in $1.26 \%$ patients, $1-2$ days treatment was prescribed in $7.17 \%$ cases, $3-5$ days in $37.55 \%$ cases, $6-7$ days in $26.16 \%$ cases, $8-10$ days in $13.08 \%$ cases and > 10 days in $8.43 \%$ prescriptions. Duration of treatment was not written in $6.32 \%$ prescriptions. Basic information of patient (Name, age, sex and complete address) was written only in $72.57 \%$ prescriptions. Complete diagnoses were written in $70.04 \%$ prescriptions. Only $88.61 \%$ prescriptions were legible and only $76.79 \%$ prescriptions were complete in terms of dose, route, strength, frequency and dosage forms (Table 2).
Drugs on EDL are only $53.25 \%$ and fixed dose combinations are $26.87 \%$ of total drugs. Dosage forms used were mostly oral $-93.51 \%$. Injectables were only $6.19 \%$ and topical forms were least $0.299 \%$ (Table 3).

Disease pattern seen was variable. Diseases of respiratory system were maximum $44.72 \%$ followed by infectious and parasitic diseases $-16.03 \%$ and diseases of digestive system - $13.92 \%$. Diseases of musculoskeletal system were $7.59 \%$, cardiovascular systems were $3.37 \%$, and of central nervous system were $4.22 \%$. Least was diseases of skin and subcutaneous tissues $-2.53 \%$ and trauma cases $-2.11 \%$. Others miscellaneous diagnoses were $5.48 \%$ (Table 4).

The pattern of diagnosis seen was: One diagnosis was written in $85.65 \%$ prescriptions, 2 diagnoses were written in $10.12 \%$ prescriptions and 3 diagnoses were written in $0.84 \%$ prescriptions and no diagnosis written in $3.37 \%$ prescriptions (Table 4). 
Table 5: Common categories of drugs prescribed to outpatients.

\begin{tabular}{|c|c|c|}
\hline & Category of drugs & Number of drugs $(\boldsymbol{\%})$ \\
\hline 1. & NSAIDs \pm serratiopeptidases & $207(20.67 \%)$ \\
\hline 2. & Opioid analgesics & $29(2.89 \%)$ \\
\hline 3. & Antibiotics & $175(17.48 \%)$ \\
\hline 4. & Anti-ulcer drugs/GIT & $94(9.39 \%)$ \\
\hline 5. & Cardiovascular drugs & $44(4.39 \%)$ \\
\hline 6. & Central nervous system drugs & $60(5.99 \%)$ \\
\hline 7. & Antihistaminics & $154(15.38 \%)$ \\
\hline 8. & Hormones & $29(2.89 \%)$ \\
\hline 9. & Multivitamins, minerals \& Enzymes & $101(10.08 \%)$ \\
\hline 10. & Expectorants \& Bronchodilators & $108(10.78 \%)$ \\
\hline
\end{tabular}

Table 6: Number of drugs prescribed per prescription - poly pharmacy.

\begin{tabular}{|c|c|}
\hline $\begin{array}{c}\text { Prescription containing Number } \\
\text { of drugs }\end{array}$ & Number of prescriptions (\%) \\
\hline One & $5(2.11 \%)$ \\
\hline Two & $17(7.17 \%)$ \\
\hline Three & $47(19.83 \%)$ \\
\hline Four & $93(39.24 \%)$ \\
\hline Five & $33(13.92 \%)$ \\
\hline Six & $20(8.43 \%)$ \\
\hline Seven & $15(6.33 \%)$ \\
\hline Eight & $6(2.53 \%)$ \\
\hline Nine and more & $1(0.42 \%)$ \\
\hline
\end{tabular}

Table 7: Problems observed in prescriptions.

\begin{tabular}{|c|c|c|}
\hline & Problem description & Number of prescriptions (\%) \\
\hline 1. & Diagnosis not written & $8(3.37 \%)$ \\
\hline 2. & Duration of treatment not written & $15(6.32 \%)$ \\
\hline 3. & Sex not written & $12(5.06 \%)$ \\
\hline 4. & Age not written & $13(5.48 \%)$ \\
\hline 5. & Date not written & $9(3.79 \%)$ \\
\hline 6. & OPD number absent & $16(6.75 \%)$ \\
\hline 7. & Signature of doctor absent & $19(8.02 \%)$ \\
\hline & Total & $\mathbf{9 2}(\mathbf{3 8 . 8 1 \%})$ \\
\hline
\end{tabular}

The most common drug groups prescribed were NSAIDs \pm serratiopeptidases, antibiotics, antihistaminics, multivitamins, minerals \& enzymes and expectorants \& bronchodilators. More than one antibiotic was prescribed in $4.64 \%$ cases (Table 5).

The incidence of polypharmacy was also common with maximum no. of drugs which were prescribed per prescription were four. $39.24 \%$ of prescriptions had 4 drugs, $19.83 \%$ had 3 drugs and $13.92 \%$ had 5 drugs per prescription (Table 6).

Various problems were also encountered in these prescriptions such as absence of diagnosis, duration of treatment not written, age and sex not written, OPD number absent and signature of doctor absent (Table 7). 


\section{DISCUSSION}

Providing the right medicine to the right people at the right time is a central priority of health care. The way to ensure this is through the effective implementation of the WHO's recommendation on rational drug policies. Rational drug use is a function of prescription practices having medical, social and economic implications. Prescription auditing is the mainstay of quality assurance in hospitals. They should address problems that have serious consequences for patients if proper treatment is not given which can minimize the misuse of drugs, plan essential drug selection and estimate the drug needs of the community. The audit data's will be of great value to health administrators, manufacturers, distributors and health professionals groups for their decision making and drafting policies.

In our study the total no. of drugs in 237 prescriptions analyzed were 1001. Therefore average number of drugs/prescriptions is 4.22 . This number is very much higher than the recommended limit of $2.0 .^{2}$ Increase in the number of average drugs per prescription may increase the risk of drug interactions, may lead to unwanted side effects and also increases the prescribing and dispensing errors. This is an important indication that educational intervention of the principles of rational pharmacotherapeutics needs to be introduced.

Drugs were prescribed by generic names in only $3.79 \%$ of cases. This figure is very low as compared to other Indian studies many of which have even reported upto $73.4 \%$ usage of generic name. ${ }^{9}$ This clearly shows how our prescribing habits are being directly influenced by the representative of the drugs companies for undue favors. Generic prescribing reduces the chances of dispensing errors which may be due to misinterpretation of like sounding names of drugs and also decreases the economic burden on the patients. Hence we should encourage generic prescribing by educational intervention methods and strict compliance to WHO drug policies.

Drugs on EDL were only $53.25 \%$. Though it was comparable with other Indian studies ${ }^{3,8}$, but was still on the lower side. There was no EDL to which the physicians could refer. A local hospital formulary will help the physicians to prescribe on an out patient basis and follow the clinical protocols.

Dosage forms used were mostly oral $-93.51 \%$. Injectables were only $6.19 \%$ and topical forms were least $0.299 \%$. Though the use of injectables was high as compared to other studies but was at par with two Indian studies which reported $7 \%$ and $6.8 \%$ use of injectables respectively. ${ }^{5,6}$ We need to reduce the unnecessary use of injectables to prevent HIV and other blood borne infections. ${ }^{10}$

Fixed dose combinations used were in $40.92 \%$ of prescriptions. This figure is comparatively higher than other studies but lower than two Indian studies which reported $75 \%$ and $60 \%$ usage of FDCs respectively. ${ }^{11,12}$ It may warrant inappropriate use of unwanted drugs which can lead to adverse effects and drug interactions. Use of fixed dose combinations should be discouraged unless strictly necessary.

Antibiotics prescribed were $17.48 \%$ of drugs. More than one antibiotic was prescribed in $4.64 \%$ of cases. This result is acceptable and as compared to a study by Gupta et al in which half of the patients i.e. $50 \%$ received more than one antibiotic this figure is much lower. ${ }^{13}$ Appropriate use of antibiotics is absolutely necessary to prevent emergence of drug resistance and should be mostly used after culture sensitivity testing. Most of the acute respiratory and acute gastroenteritis cases are viral in nature and may not need antibiotics. An antibiotic policy should be formulated so that the clinicians can use them judiciously according to patients need.

Maximum number of prescriptions was written for a duration of 3-5 days (37.55\%) which was quite appropriate followed by 6-7 days (26.16\%). Basic information of patients like name, age, sex and complete address was written only in $72.57 \%$ of prescriptions. Complete diagnosis was written only in $70.04 \%$ of prescriptions. Completeness in terms of dose, route, strength, frequency and dosage forms was seen only in $76.79 \%$ of prescriptions. All these information should be complete in all respects. Only $88.61 \%$ of prescriptions were legible. Therefore proper training and education of physicians is necessary regarding legibility and completeness of prescriptions in all aspects.

Poly pharmacy was clearly visible in our data. Maximum number of prescriptions i.e. $39.24 \%$ had four drugs each followed by three in $19.83 \%$ and five drugs in $13.92 \%$ of prescriptions. Poly pharmacy is a very common practice now days as is reported by various studies. ${ }^{14,15}$ It is of concern in those patients with various co-morbidities as it increases the chances of drug interactions.

The most common disease pattern seen in patients attending the medicine OPD of our hospital was diseases of respiratory system accounting for $44.72 \%$ of cases followed by infectious and parasitic diseases which were $16.03 \%$ and diseases of digestive system (GIT) which were $13.92 \%$ of cases.

The most Common categories of drugs prescribed to outpatients were NSAIDs \pm serratiopeptidases (20.67\%) followed by antibiotics which were $17.48 \%$, antihistaminics $15.38 \%$, multivitamins, minerals \& enzymes $10.08 \%$ and Expectorants \& Bronchodilators $10.78 \%$. Doctors should not prescribe unnecessary medicines like multivitamins, minerals, enzymes and i.v. saline unless absolutely required by the patient. They should adhere and prescribe from the Essential drug list. 
Ninety two prescriptions (38.81\%) had various anomalies. Diagnosis was not written in $3.37 \%$ of cases while duration of treatment was not written in $6.32 \%$ of prescriptions. However age and sex were absent in $5.48 \%$ and $5.06 \%$ of cases respectively. Date was not written in $3.79 \%$ of cases and OPD number was absent in $6.75 \%$ of prescriptions. Signature of doctor was absent in $8.02 \%$ of prescriptions. All these anomalies encountered in the collected data indicate that there is a huge scope for improvements in the prescriptions patterns in our hospital.

\section{CONCLUSIONS}

Prescription auditing gives a clear picture of the prescribing practices in our hospital setting. There is a need for improvement in the standards of prescription patterns in all aspects. In order to improve the quality of care, an action plan should be formulated and recommendations for changing the present prescribing practices are set either by providing the hospital doctors with the Standard Treatment Guidelines, EDL and Antibiotic policy or by following the information, education, and communication (IEC) interventions. After an agreed period re-auditing should be done to demonstrate that the changes have been implemented and improvements made in deficient areas.

Apart from promoting rational pharmacotherapeutics these measures will also create a conducive working environment and promote behavioral changes.

Funding: No funding sources

Competing interests: None declared

Ethical approval: Not required

\section{REFERENCES}

1. Hogerzeil HV. Promoting rational prescribing: an international perspective. $\mathrm{Br} \mathrm{J}$ Clin Pharmacol 1995;39:1-6.

2. WHO. How to investigate drug use in health facilities: Selected drug use indicators. Geneva: World Health Organization; 1993. WHO/DAP 1993;1:1-87.
3. Biswas NR, Jindal S, Siddiquei MM, Maini R. Patterns of prescription and drug use in ophthalmology in a tertiary hospital in Delhi. Br J Clin Pharmacol 2001;51:267-9.

4. Devi DP, George J. Diabetic Nephropathy: Prescription trends in tertiary care. Indian J Pharm Sci 2008;70:374-8.

5. Rishi RK, Sangeeta S, Surendra K, Tailang M. Prescription audit: experience in Garhwal (Uttaranchal), India. Trop Doct 2003;33:76-9.

6. Maini R, Verma KK, Biswas NR, Agrawal SS. Drug utilization study in dermatology in a tertiary hospital in Delhi. Indian J Physiol Pharmacol 2002;46:10710.

7. Rehan HS, Lal P. Drug prescribing pattern of interns at a government healthcare centre in northern India. Trop Doct 2002;32:4-7.

8. Hazra A, Tripathi SK, Alam MS. Prescribing and dispensing activities at the health facilities of a nongovernmental organization. Natl Med $\mathbf{J}$ India 2000;13:177-82.

9. Karande S, Sankhe P, Kulkarni M. Patterns of Prescription and Drug Dispensing. Indian J Pediatr 2005;72:117-21.

10. Hutin YJF, Hauri AM, Armstrong GL. Use of injections in healthcare setting worldwide, 2000: literature review and regional estimates. BM] 2003;327:1075-9.

11. Kastury N, Singh S, Ansari KU. An audit of prescription for rational use of fixed dose drug combinations. Indian J Pharmacol 1999;31:367-9.

12. Chakrabarti A. Prescription of fixed dose combination drugs for diarrhoea. Indian $\mathbf{J}$ Med Ethics 2007;4:165-7.

13. Gupta N, Gupta, D, Sharma, Garg SK, Bhargava VK. Auditing of prescriptions to study utilization of antimicrobials in a tertiary hospital. Indian $\mathbf{J}$ Pharmacol 1997;29:411-5.

14. Patel V, Vaidya R, Naik D, Broker P. Irrational drug use in India. J Postgrad Med 2005;51:9-12.

15. Vengurlekar S, Shukla P, Patidar P, Bafna R, Jain S. Prescribing pattern of antidiabetic drugs in Indore city hospital. Indian J Pharm Sci 2008;70:637-40.

doi: 10.5455/2319-2003.ijbcp003812

Cite this article as: Abidi A, Gupta S, Kansal S, Ramgopal. Prescription auditing and drug utilization pattern in a tertiary care teaching hospital of western UP. Int J Basic Clin Pharmacol 2012;1:184-90. 